\title{
Article
}

\section{Morphology and elemental analysis of freshly emitted particles from packed-bed domestic coal combustion}

\author{
Masilu Daniel Masekameni ${ }^{1 *}$, Tafadzwa Makonese ${ }^{3}$ and Isaac Tebogo Rampedi ${ }^{2}$ \\ ${ }^{1}$ Division of Occupational Health, School of Public Health: University of the Witwatersrand, \\ Parktown, 2193 \\ ${ }^{2}$ Department of Geography, Environmental Management and Energy Studies, University of Johannesburg, \\ Johannesburg, South Africa. \\ ${ }^{3}$ Sustainable Energy Technology \& Research Centre, Faculty of Engineering and the Built Environment, \\ University of Johannesburg, \\ P. Bag 524, Johannesburg 2006, South Africa \\ * Correspondence: daniel.masekameni@wits.ac.za
}

\begin{abstract}
This study was conducted in a laboratory-controlled environment aiming at studying the physical properties and elemental composition of coal combustion particles in a brazier. Particles were sampled $\sim 1 \mathrm{~m}$ above the stove using a partector, where particles were collected on gold Transmission Electron Microscopy (TEM) grids and polycarbonate filters for TEM and inductively coupled plasma mass spectrometry (ICP-MS) analysis, respectively. Particles for elemental analysis collected on a $37 \mu \mathrm{m}$ polycarbonate filters whereby a Gillian pump was used to draw in air. During sampling, a $2.5 \mu \mathrm{m}$ cyclone was attached to the sampling cassette to isolate larger particles. The results have shown that combustion particles emitted during the early stage of combustion where single spherical particles with a diameter of around $450 \mathrm{~nm}$. As the combustion progresses, the particle diameter gradually decreases and the morphology changes to accretion chain and fluffy bead structure for the flaming and char-burning phase, respectively.
\end{abstract}

Keywords: physical properties; TEM; ICP-MS; elemental composition

\section{Introduction}

Despite effort to reduce dependent on solid fuel in residential sector, over 3 billion people to date continue to burn coal and wood daily for cooking and space heating (Smith et al., 2007, 2009; Zhang and Smith, 2007). Particulate matter has been singled out as a form of pollutant, which continues to pose a significant threat to the environment and human health. Suspension of particles in the atmosphere is a contribution of natural and anthropogenic sources (Mc Donald and Biswas, 2004; Chafe et al., 2015). Several studies have indicated a significant increase in emissions of particles from various anthropogenic activities such as transport, mining and combustion (Smith and Liu, 1994; Kumar et al., 2014; Forouzanfar et al., 2015; Kumarathasan et al., 2018). However, it is further illustrated that the suspension of particles is influenced by several factors such as the meteorological conditions, particle diameter and chemical property (Köylu, Xing and Rosner, 1995; Nussbaumer et al., 2001; Petaloti et al., 2006). Combustion sources are reported to have contributed to over $90 \%$ of the total mass of particles in the atmosphere (Smith et al., 1994; Alexander, Crozier and Anderson, 2008; Zhou et al., 2015). Significant progress has been made to date to evaluate the health impacts of particles on human health (Zhang et al., 2000; Jalava et al., 2010; Rainey, Vaganay and MacIntyre, 2016). The contribution of particles in the sub-micron size diameter was found to have a higher residence time in the atmosphere and further associated with higher deposition in human's respiratory system (Meij and Winkel, 2007; Sippula, 2010; Silva et al., 2012).

Several epidemiological studies have pointed out that particles in the nano-region are highly associated with the infection of the lower respiratory tract, cardiovascular system disruption and 
morbidity (Oberdörster, 2001; IARC Working Group on the Evaluation of Carcinogenic Risks to Humans, 2010; Kumar et al., 2010; Lim et al., 2012). Despite significant effort made by several authors associating nanoparticles with severe health impacts, fewer studies have been done to investigate the morphology of particles, from packed-bed domestic coal combustion (i.e. shape, size and chemical properties) (Li et al., 2003; Kocbach et al., 2005; Torvela et al., 2014; Zhang et al., 2018). In addition to the health risks, combustion particles have been associated with environmental impacts (Chakrabarty et al., 2010; Chung, Ramanathan and Decremer, 2012). Sub-micron particles are often enriched with black carbon/ brown carbon, which contributes to the physicochemical processes occurring in the troposphere. Combustion particles from low-temperature combustion can absorb solar radiation from the sun (Chakrabarty et al., 2010; Liu et al., 2014; Tóth et al., 2014a). Furthermore, combustion particles also contribute to the light scattering effects, and provide an active site for the uptake of several chemical species and trace gases(Bond et al., 2002; Hand et al., 2005; Gwaze, 2007). In combustion sciences, more emphasis has been placed on the characterization of emissions of submicron particles in the transport sector and large-scale combustion processes such as power plants (Streets and Waldhoff, 2000; Petaloti et al., 2006; Meij and Winkel, 2007). However, very few studies to date have studied the morphology of particles emitted from small scale coal combustion technologies even though significant associated risks have been reported in countries like China, India and Finland (Zhang et al., 2000; He, Liang and Jiang, 2002; Niemi et al., 2006; An et al., 2007; Smith et al., 2007; Wilkinson et al., 2009; Chafe et al., 2015).

Characterization of the organic fractions emitted from domestic coal burning technologies has been reported globally (Nussbaumer et al., 2001; Zhang et al., 2012; Torvela et al., 2014). However, very few studies focused on the characterization of trace elements emitted from residential coal burning (Petaloti et al., 2006; Vejahati, Xu and Gupta, 2010; Silva et al., 2012). Studies conducted in China have slightly reported the possible health effects of trace elements emitted from residential coal burning (Zhang) (Zhang and Smith, 2007; Liu et al., 2008; Zhang et al., 2008). In the province of Guizhou, over 3000 people suffered arsenic poisoning, bone deformation, human selenosis and fluorosis because of exposure from residential coal burning (Ando et al., 2001; Finkelman et al., 2002; Silva et al., 2012; Zhou et al., 2015). Furthermore, it was also established that the health effects of trace elements from coal-burning would vary according to coal properties and exposure scenarios (Chang et al., 2004; Xu et al., 2011; Makonese, Masekameni and Annegarn, 2017).

Coal used in domestic combustion technologies often contains a lower amount of volatile organic compounds, which influences conditions for complete combustion (Moreira Dos Santos, De Almeida Azevedo and De Aquino Neto, 2004; Tissari et al., 2008; Frey, 2014; Torvela et al., 2014). Consequently, during ignition, coal requires a catalyst to burn. Often, wood kindling is used for ignition due to the inherent higher volatility of this fuel (Makonese, 2015). The formation of particles is high at low-temperature conditions and during incomplete combustion conditions, where soot might be formed comprising of elemental carbon, black carbon and gas precursor to aerosols as polycyclic aromatic hydrocarbons (PAHs) (Wang and Luo, 2009; Tiwari et al., 2014).

Previous studies reported emissions from small-scale combustion as average concentration of particles above $2.5 \mu \mathrm{m}$ over the entire burn cycle, with less emphasis on monitoring emissions at specific combustion phases (Makonese et al., 2015, 2017a). However, combustion in fixed-bed systems varies at different stages (ignition, pyrolysis and char burning) (Masekameni, Makonese and Annegarn, 2014; Masekameni et al., 2018). During the moisture contained in the wood, kindling turn to reduces the combustion temperature leading to the release of a thick white plume comprising of condensing volatile organic compounds escaping without being burned (Braasch et al., 2013). At the flaming phase, the combustion conditions improve as the moisture contained in the fuel is driven out (Wei et al., 2012). The char burning phase is associated with a stable fire where char burns homogeneously in the presence of sufficient air supply (Huangfu et al., 2014). However, other literature are in contrary with what was reported, indicating that fine particles, which are said to have health consequences are mostly emitted during the char burning phase and flaming phase (Tiwari et al., 2014; Masekameni et al., 2018). It is, therefore, essential to evaluate the physical and elemental composition of coal particles at each combustion phase to further understand mechanisms on particle formation, distribution and identification. 
In South Africa, especially in the central plateau of the Highveld region coal burning using unvented stoves continue to be a significant source of energy for domestic cooking and space heating (Wentzel et al., 1999; Balmer, 2007; Makonese et al., 2017a). Efforts to reduce dependence on coal at the domestic level have been commissioned before but not yet fully implemented (Winkler, 2005; Kimemia and Annegarn, 2011; Bonjour et al., 2013). However, studies suggest that there is an insignificant shift from coal usage to clean energy alternatives due to the abundance of coal in this region and cost of alternative clean energy sources, hence the pollution levels indoors and outdoors remains high (Balmer, 2007; Winkler, 2007; StatsSA, 2017). From the reviewed literature, it was noted that moisture content, coal grade, stove ventilation, fire ignition method and coal particle size affect performance profiles (Huangfu et al., 2014; Makonese et al., 2017b). However, in this paper, the primary dependent variables were the fire ignition method and ventilation rates. In 2004, the South African government developed and rolled-out the use of top-lit updraft (TLUD) as an interim household air pollution intervention (Le Roux, Zunckel and Mccormick, 2009). It is suggested that the use of top-lit updraft reduces emissions of particles by $80 \%$ relative to the bottom lit updraft ignition (Le Roux, Zunckel and Mccormick, 2009; Masekameni, Makonese and Annegarn, 2014; Makonese et al., 2017b). Therefore, based on the South African government's adoption of the strategy, the use of high ventilation stoves and the TLUD method for optimum performance requires further investigation to validate such claims (Wei et al., 2012; Makonese et al., 2014; Makonese, 2015).

Transmission electron microscopy (TEM) and scanning electron microscopy (SEM) are important tools to study the shape and morphology of aerosol particles (Schneider et al., 2006; Gwaze, 2007). Equipped with energy dispersive X-ray (EDX) or electron energy loss (ELL) spectroscopy, they give information on the elemental composition of the particles of interest (Nussbaumer et al., 2001). While TEM allows a higher resolution down to the Nano and atomic scale, SEM usually has better contrast (Kocbach et al., 2005). For TEM, very thin grids (often copper/ gold) coated with a carbon film/gold, are used. The quality of this film is essential to obtain a good resolution(Mathis et al., 2005). If samples are used for quantitative analysis (e.g. of the size distribution), care must be taken to have defined size fractions during the sampling process (Nussbaumer et al., 2001; Bond et al., 2006). In addition to particle morphology, the correct identification and determination of the elemental composition rely on the use of effective analytical techniques. Inductive couple mass spectrometry (ICP-MS) has been widely used to study the elemental composition of combustion particles (Graham et al., 2002; Suzuki, 2006; De Jong et al., 2008; Zhang et al., 2012; Forouzanfar et al., 2015). In this study, we have evaluated the physical properties and selected elemental composition ( $\mathrm{Na}, \mathrm{Mg}, \mathrm{Al}, \mathrm{Si}, \mathrm{K}, \mathrm{Ca}$, $\mathrm{Ti}, \mathrm{V}, \mathrm{Cr}, \mathrm{Mn}, \mathrm{Fe}, \mathrm{Co}, \mathrm{Ni}, \mathrm{Cu} 63, \mathrm{Zn}$ ) generated during residential coal burning at three combustion phases (ignition, flaming and cooking).

The current practice in determining the state of air quality in South Africa is through monitoring of indicator pollutants such as particulate matter, NOx, $\mathrm{O}_{3}$ and $\mathrm{SO}_{2}$ (GroundWork, 2016; SANS, 2005; Moolla, Curtis and Knight, 2015). Part of the government's effort to assess the effectiveness of clean energy alternatives is to conduct source apportionment. Therefore, the study on the morphology and chemical analysis are needed to conclusively determine source contribution and further our understanding of pollutant source distribution. The study is limited to D-grade coal burned in a high ventilated stove and lit with a TLUD ignition method for the three combustion phases (ignition, flaming and char burning).

\section{Materials and Methods}

\subsection{Experimental stove and fuel analysis}

D-grade coal was burned in a high-ventilated stove lit using top-lit ignition method in a laboratory-controlled environment in three distinct combustion phases (ignition, flaming and char burning). In the present study, due to variations of field-based factors, several variables were kept constant (Ventilation rates, height of grate, size of fuel, ignition method and fuel). The stove characteristics such as grate and stove height are shown in Figure 1. 

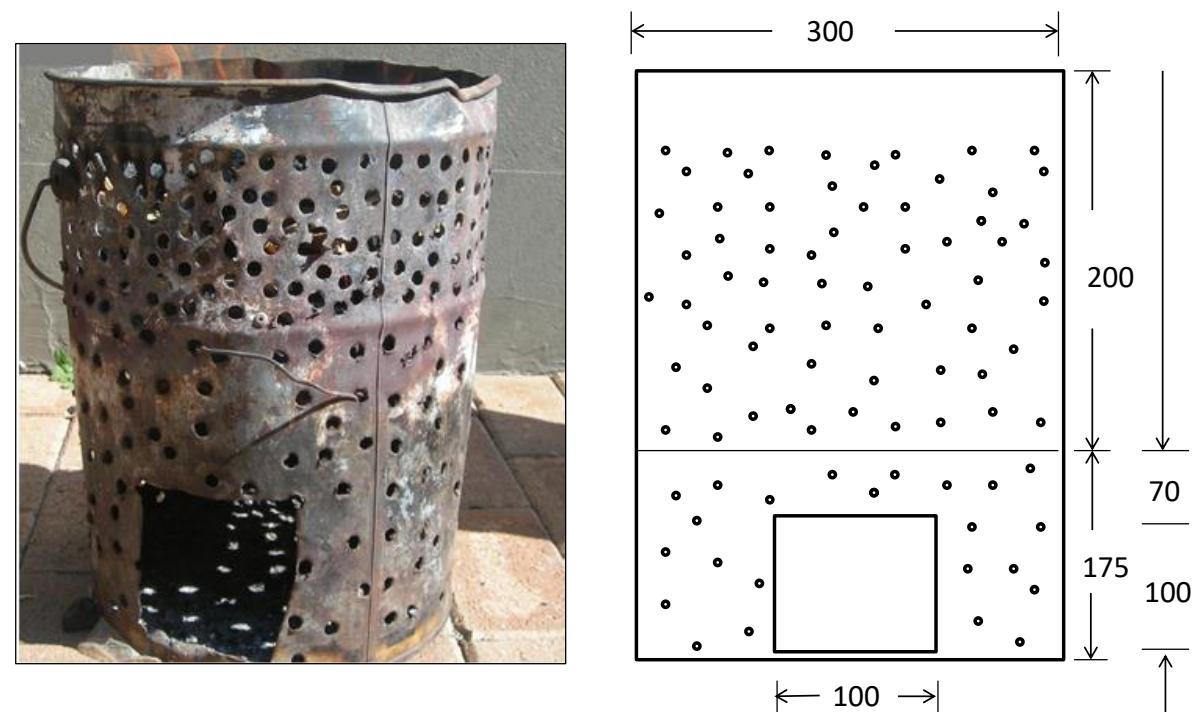

Figure 1. A photographic and schematic representation of a high ventilation field procured optimized brazier stove used in the experiments (Not drawn to scale - dimensions are in $\mathrm{mm}$ ) (Makonese et al., 2017b).

Coal particle size was determined by sieving the coal to a $40 \mathrm{~mm} \times 60 \mathrm{~mm}$ diameter mesh. Coal used in this study was analysed by an independent laboratory, using the appropriate recommended methods (Bureau Veritas Inspectorate Laboratories (Pty) Ltd). Experimental results presented in this paper have been based on the proximate and ultimate $\mathrm{D}$ grade coal analyses conducted on an air dried basis (Results of the coal analyses are given in the results section in Table 2). During the TLUD ignition method, the fuel ordering entailed placing $2500 \mathrm{~g}$ of coal on the grate, followed by the paper $(35 \mathrm{~g})$, wood $(400 \mathrm{~g})$, and the remaining $1500 \mathrm{~g}$ of coal on top. Details on the division of the combustion phases, fuel properties and ignition method are presented in details in published literature (Masekameni, Makonese and Annegarn, 2014; Masondo et al., 2016; Makonese et al., 2017b).

\subsection{Particle sampling}

Particles were collected on TEM gold grids and polycarbonate membrane filters for TEM and ICP-MS analyses, respectively. The TEM gold grids were placed on a grid holder from the partector aerosol dosimeter TEM sampler (Naneos particle solutions, Switzerland), and the particles were deposited directly onto the grid. The sampling train included a Teflon tube connecting the partector inlet to the sampling cassette fitted with a $2.5 \mu \mathrm{m}$ cyclone. The partector was set at a flow rate of 2.8 $\mathrm{L} / \mathrm{m}$ according to the cyclone's specification. Sampling for ICP-MS was done using polycarbonate membrane filters $(37 \mathrm{~mm}$ ). The exhaust was drawn onto the membrane filter inside a cassette by a GilAir Plus pump (Model) set at a flow rate of $2.2 \mathrm{~L} /$ minute. The filters were changed at each combustion phase (ignition, flaming and char burning phases).

\subsubsection{Preparation of filters}

A total of 12 (3 samples at each combustion phase), $37 \mathrm{~mm}$ diameter polycarbonate membrane filters with a pore size of $0.08 \mu \mathrm{m}$ were stored in a controlled laboratory environment prior field sampling. The temperature ranged from $22-23{ }^{\circ} \mathrm{C}$ and the humidity was recorded at $35 \%$. The filters were conditioned for 24 hours and pre-weighed using a Sartorius electronic microbalance (modelCPA225D, supplied with a balance pan) with a minimum resolution of $0.001 \mathrm{mg}$ (i.e., one microgram) and a precision of $0.001 \mathrm{mg}$ (Figure 2). The same procedure was repeated after a three-hour burn cycle sampling of particulate matter was completed. A field blank was handled the same way with the field filter. However, the field blank was not exposed to the particulate matter. The use of field blank is to overcome or account for moisture loss due to meteorological condition particularity 
during transportation and contamination during filter handling. The determination of the final mass was calculated using equation 1.

Final mass $=$ Field filter $($ post - pre $)+$ field blank $($ post - pre $)$

Equation 1

Where the field filter post mass is the mass collected from the filter after sampling while the field pre-mass is the mass recorded before sampling. The field blank post and pre is the mass recorded after transportation and before transportation of filters respectively.

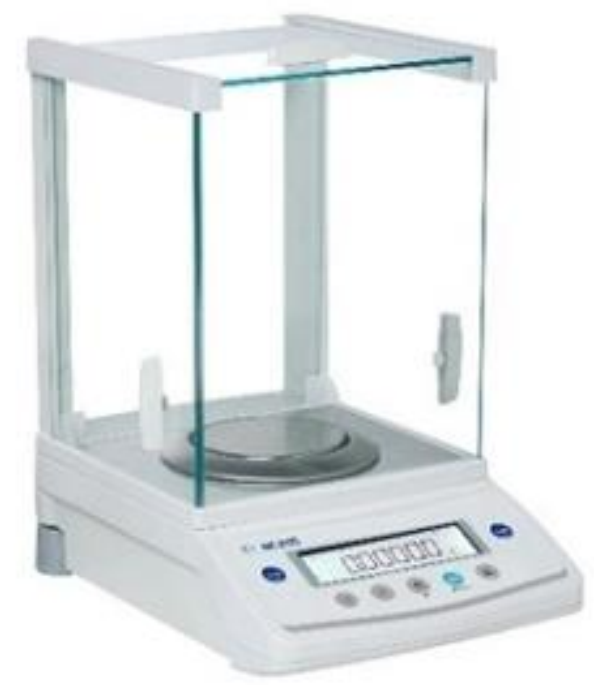

Figure 2. Sartorius electronic microbalance (model- CPA225D).

\subsubsection{Inductively coupled mass spectrometry}

The sample filters for ICP-MS analysis were folded and placed inside pre-cleaned microwave digestion vessels $9 \mathrm{~mL}$ supra pure (Merc) nitric acid ( $\mathrm{HNO}_{3}$ ), and $1 \mathrm{~mL}$ supra pure (Merc) hydrogen peroxide $\left(\mathrm{H}_{2} \mathrm{O}_{2}\right)$ was added to each vessel. A reagent blank was included with the batch as a control. The vessels were closed and placed in a Mars 6 microwave. The digestion method made the vessels ramp to 200 for 20 minutes, and hold the temperature for another 15 minutes. The samples were then quantitatively transferred to a $50 \mathrm{~mL}$ volumetric flasks and made up to the mark using $18.2 \mathrm{M} \Omega / \mathrm{cm}$ ultrapure water. Calibration standards of $0 \mu \mathrm{g} / \mathrm{L}, 0.1 \mu \mathrm{g} / \mathrm{L}, 0.5 \mu \mathrm{g} / \mathrm{L}, 1.0 \mu \mathrm{g} / \mathrm{L}, 5.0 \mu \mathrm{g} / \mathrm{L}$ and $10 \mathrm{ug} / \mathrm{L}$ were prepared from $100 \mathrm{mg} / \mathrm{L}$ NIST traceable stock standards. The samples were then filtered using a $0.45 \mu \mathrm{m}$ syringe filter and diluted another ten times $(1 \mathrm{ml}$ diluted to $10 \mathrm{ml})$ before analysis by ICPMS. The blank filter analysis using the ICP-MS technique was carried out in the same manner as the actual sample filters.

\subsubsection{Transmission electron microscopy (TEM)}

Combustion smoke particles were imaged for their morphologies using JEM-2100 is a multipurpose, $200 \mathrm{kV}$ analytical electron microscope at the University of Johannesburg. The instrument is manufactured by Jeol Ltd from Akishima, Tokyo, Japan. A TEM has been used to study the semi-structure especially in particles with a smaller diameter in contrast to an optical microscope, which uses light as an illumination source for imaging. The TEM uses electrons, which provide an opportunity to separate arrangements of atoms in small structure/ combustion soot aggregates (Kocbach et al., 2005; Wang et al., 2018). The TEM microscope combines the JEM-2100 optic system with an advanced control system for enhanced ease of operation.

\section{Results and Discussion}

\subsection{Morphology of coal particles from TEM analysis}




\subsubsection{Morphology of smoke particles emitted during the ignition phase}

We have used TEM analysis to study and distinguish different smoke particle morphologies similar to previously conducted studies (Pósfai et al., 2004; Chakrabarty et al., 2010; Tóth et al., 2014b). Figure 3 presents, the morphologies of smoke particles emitted during residential coal combustion. The morphologies presented herein are from the ignition phase.
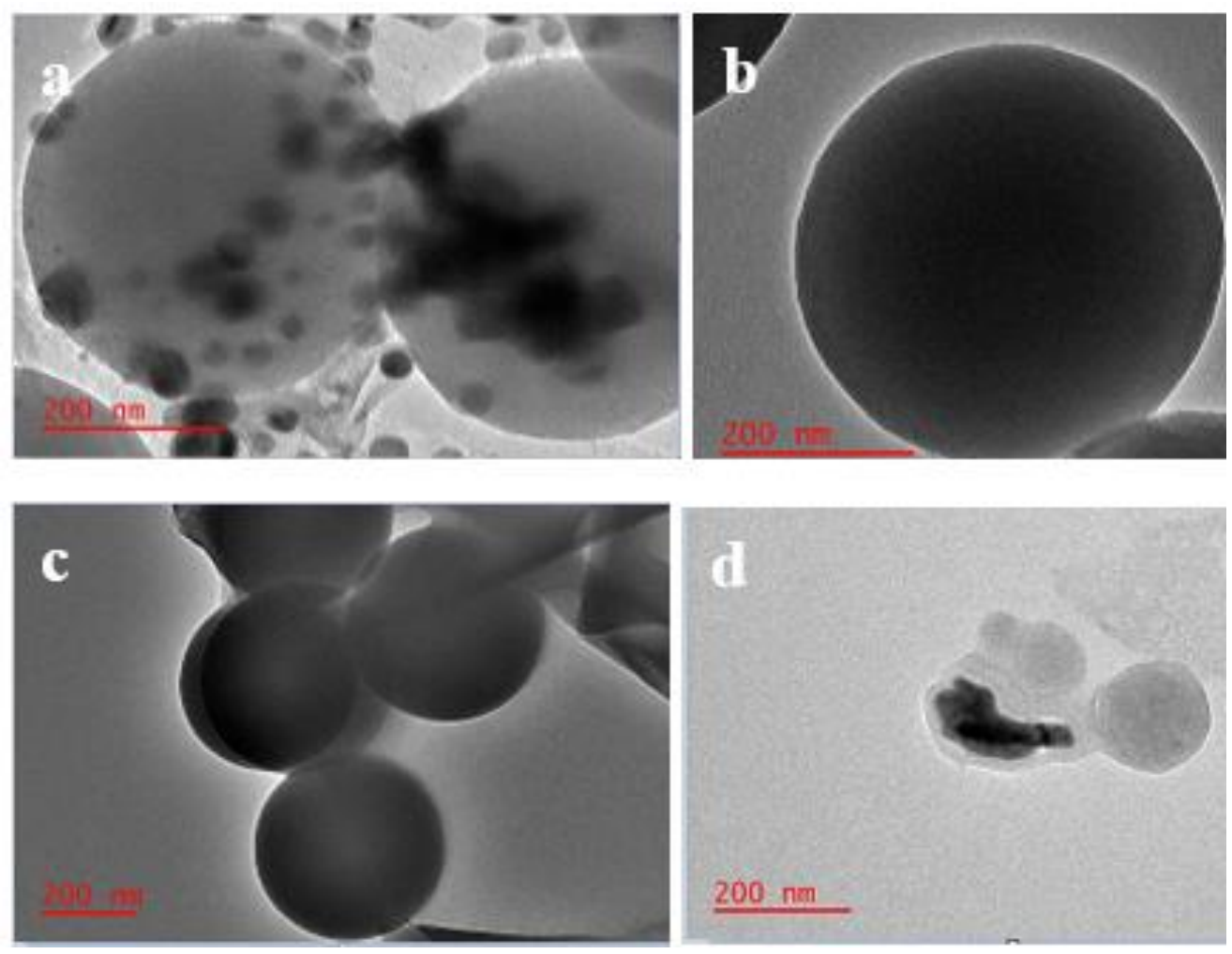

Figure 3. TEM images of particles emitted during the ignition phase- a) carbonaceous spherical particle, b) internal structure of spherules with evidence of aggregates, c) Onion-like structured soot particles.

Figure 3a shows a spherical organic particle with the same characteristics of tarballs collected from low-temperature combustion during the ignition phase. This finding suggests that the spherical particles are emitted because of low-temperature combustion. Posfai et al. (2003) contended that these carbonaceous particles are formed in smouldering fires and that they increase in abundance in the atmosphere as the plume ages.

Furthermore, Posfai et al. (2004) reported similar morphologies. However, the source contribution was veld fires, which is often dominated by biomass burning. Figure $3 b$ shows large organic spherical particles infused with diffusion accretion chains forming soot. It was observed that since these particles were collected at $1 \mathrm{~m}$ above the stove, the morphology might change with an increase in the height of sampling due to ageing.

Figure $3 c$ shows particle growth as the spherical organic particles fuse probably due to collision. Thujadeen et al. (2015) contended that particle-particle collisions are the dominant particle growth mechanism during combustion even though the particles may restructure or rearrange after the collision and fail to coalesce. Similar morphologies to those presented in this paper were observed from biomass burning fires (Li et al., 2003; Hand et al., 2005; Cong et al., 2010; Thajudeen, Jeon and Hogan, 2015). Figure 3d displayed an onion-like structure with disordered graphic layers under the high-resolution TEM image (Wang et al., 2018; Zhang et al., 2018).

Spherical organic particles presented in the above figures indicate a homogeneous structure (spherical) showing darker and lighter areas under the TEM. The spherical organic particles have properties similar to tarballs from biomass burning. Similar results were observed and reported in previous studies Martin et al. (1998), Gelencser et al. (2003), Gao et al. (2003). However, the existing 
literature suggests that tarballs are only released as a consequence of smouldering wood burning fires. Several scholars have indicated that tarballs are not emitted during coal or oil combustion (Katrinak et al., 1992; Ramsden and Sibaoka, 1982; Parungo et al., 1992; Posfai et al., 2010).

\subsubsection{Morphology of coal particles emitted during the flaming phase}

During the flaming phase, particle diameter reduced compared to the ignition phase as in figure $3 a$ and $b$. The formation of the spherical particles during ignition is thought to be influenced by the release of polar compounds during smouldering fires. During flaming, fewer polar compounds, which affect particle growth, are emitted compared to the ignition stage. The particles observed using TEM indicate fused small particles with diffusion accretion chains with similar characteristics to soot (Figure $4 \mathrm{a}, \mathrm{b}$ ). Soot contains aggregates of small particles often in the diameter of less than $30 \mathrm{~nm}$. A morphology similar to the present study was reported in Li et al. (2003). However, Li et al. (2003) investigated the morphology of particles in ageing smoke from the wood fire. It is important to note that in the current study the images were obtained from freshly produced particles.

A well-arranged morphology consisting of single particles can be seen in figure $4 \mathrm{~b}$. It was reported in previous literature that particle diameter decreases as the combustion conditions improve (Zhang et al., 2012; Tiwari et al., 2014; Masekameni et al., 2018)(Zhang et al., 2012; Tiwari et al., 2013; Masekameni et al., 2018).

In the study by Li et al. (2003) and Posfai et al. (2004), there was an increase on the number of tar balls in samples collected far field, suggesting particle growth due to the condensation of organic gases or transformation due to collision with other organic atmospheric particles. In our study, we have established a mechanism to which particles transform as the combustion progresses. It was established that as coal heats up, it swells and cracks open. It is through the cracks that organic particles are released and depending on the ignition method and combustion condition, a brown to thick white plume is evident and may pass through a cold zone above the burning coal to the ambient air (Wentzel et al., 1999; Masekameni, Makonese and Annegarn, 2014; Makonese, 2015). It was demonstrated that as the combustion progresses fine particles often enriched with low volatile organic gases are emitted (Masekameni et al., 2018). Furthermore, particle growth is as a result of the water injection in the coal and released as water vapour as the coal pyrolysis. Therefore, the establishment of accretion chains may be caused by coagulation of particles directly emitted from the flaming phase (Makonese, 2015; Makonese, Masekameni and Annegarn, 2017). As coal fully pyrolysis, fluffy micro-structures are formed and have the same characteristics as soot particles.
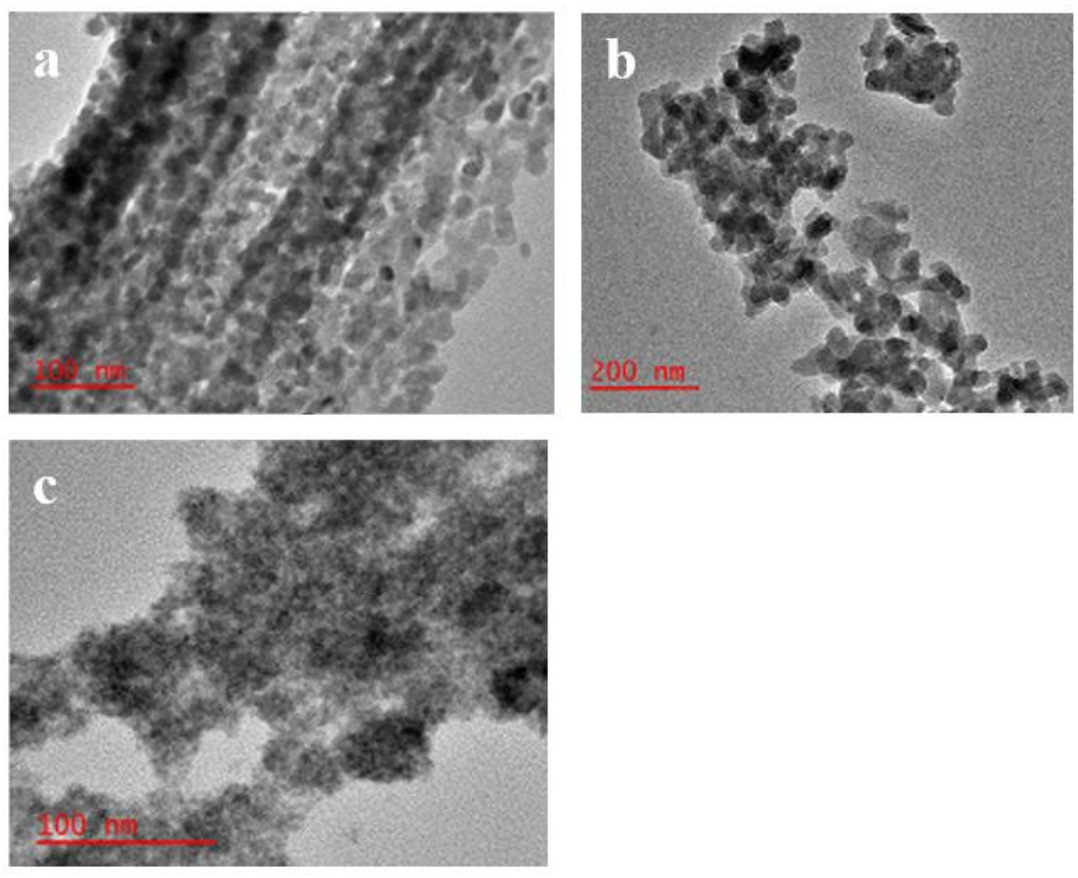
Figure 4. TEM images of carbonaceous particles emitted during the flaming phase- a) Carbonaceous soot particle showing as aggregates, b) A more established and well-arranged accretion chain, c) fluffy micro-structure resembling the formation of soot.

In summary, the results presented herein builds on the work by Makonese (2015) and Toth et al. (2014), which recommended further studies to reaffirm the existence of spherical organic particles, tarballs and related particle formation mechanisms in the domestic combustion process. We therefore, confirm that spherical organic particles with similar characteristics to tarballs are emitted as a consequence of smouldering combustion conditions. In this study, we have demonstrated that residential coal burning is a source of tarball like spherical organic particle emissions.

\subsubsection{Morphology of coal particles emitted during the char burning phase}

Figure 5 shows images of particles collected during the char burning stage of coal-combustion in a typical brazier. During the char-burning phase, as described in the literature, almost all volatile organic compounds have been released during the ignition and flaming phases (Masekameni et al., 2014; Makonese et al., 2017; Roden et al., 2007). This results in the emission of non-carbonaceous matter, usually in the form of mineral particles from the burning char. In this stage, the fire burns uniformly in sufficient oxygen supply, and particles emitted during this stage are similar to ash. The mineral particles are irregular in shape and tend to be much bigger in diameter compared to soot and homogeneous spherical organic particles. According to Wang et al. (2009), these particles are composed of crucial mineral elements including $\mathrm{Si}, \mathrm{Ca}, \mathrm{Al}, \mathrm{Fe}, \mathrm{Na}, \mathrm{K}, \mathrm{Mg}$, and $\mathrm{P}$.

However, this study did not employ EDX to semi-quantitatively determine the composition of each mineral particle. It is recommended that further studies be carried out to determine the elemental composition of specific mineral particles emitted during the char burning stage of domestic fixed-bed coal combustion. This study has employed ICP-MS to ascertain the elemental contribution of each combustion stage to the overall emissions of elements across the entire burn cycle (discussed in more detail in Section 3.2).
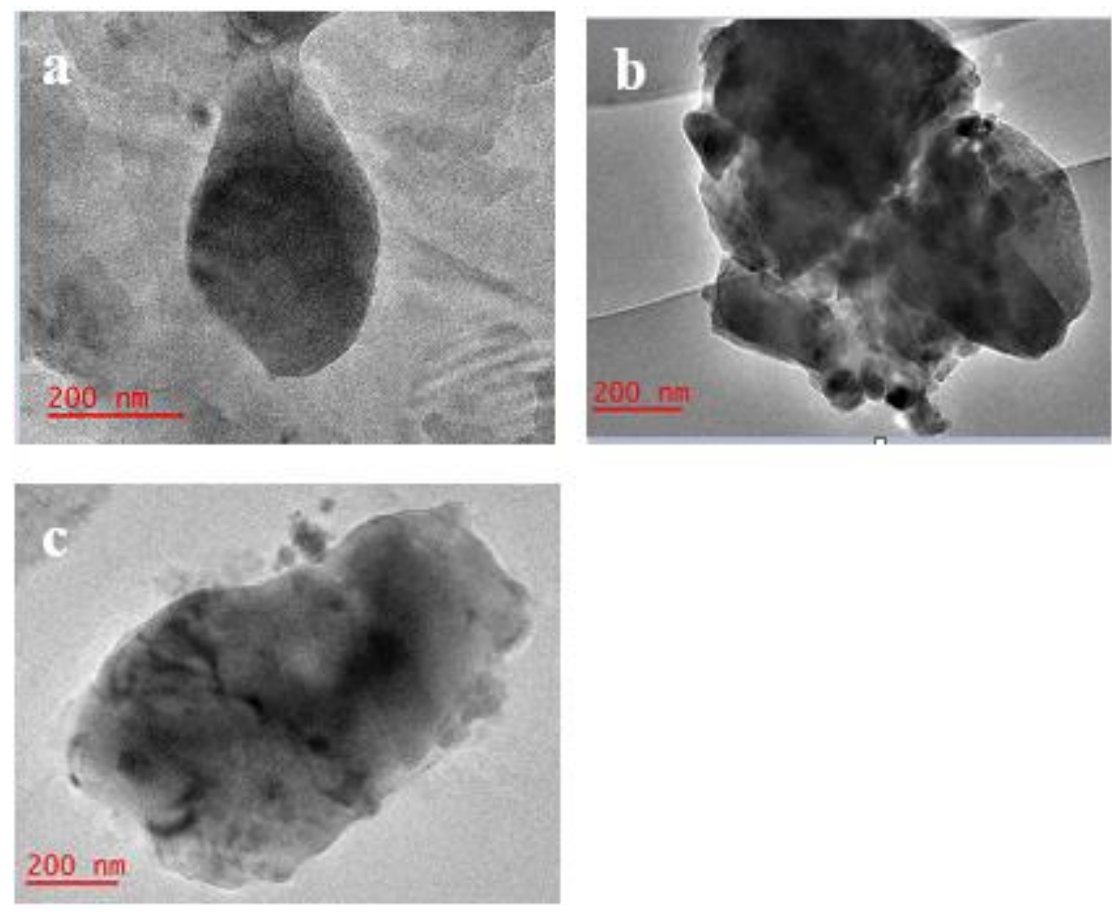

Figure 5. TEM images of particles emitted during the char burning phase- a) irregular structure of semi-spherical particles, b) evidence of mineral particles infused with small carbonaceous particles, c) A fully established macro-structure indicating the presence of non-water soluble compounds.

3.3. Elemental analysis of coal combustion particles from three distinct combustion phases (i.e. ignition, flaming and char burning) 
Table 1 presents ICP-MS results of selected trace elements collected during the three combustion phases (ignition, flaming, and char burning) and across the entire burn cycle. During the ignition phase calcium $(\mathrm{Ca})$, silicon $(\mathrm{Si})$, Iron $(\mathrm{Fe})$, potassium $(\mathrm{K})$ constituted the highest percentage released. The ICP-MS results, especially on the emission of $\mathrm{Si}$ and $\mathrm{K}$, suggest a particle partitioning similar to previous studies (Hand et al., 2005; Meij and te Winkel, 2007; Zhang et al., 2018). The smoke particles with high silicon content can be used as a marker for coal combustion processes; while the smoke particles with high potassium suggest emissions from biomass burning in this case wood used for ignition.

Table 1. Elemental composition results from inductively coupled plasma mass spectrometry (ICPMS) analysis.

\begin{tabular}{|c|c|c|c|c|c|c|c|c|c|c|c|c|c|c|c|}
\hline \multirow[t]{2}{*}{ Combustion phase } & \multicolumn{15}{|c|}{$\begin{array}{c}\text { Elements } \\
(\mu \mathrm{g} / \mathrm{g})\end{array}$} \\
\hline & $\mathbf{N a}$ & Mg & Al & Si & $\mathbf{K}$ & $\mathbf{C a}$ & $\mathbf{T i}$ & V 51 & $\mathrm{Cr}$ & Mn & $\mathbf{F e}$ & Co & $\mathrm{Ni}$ & $\mathrm{Cu} 63$ & $\mathrm{Zn}$ \\
\hline Ignition & 0.8 & 0.2 & 0.2 & 2.3 & 1.4 & 3.9 & 0.1 & 0.0 & 0.1 & 0.0 & 0.8 & 0.0 & 0.1 & 0.0 & 0.2 \\
\hline$\%$ contribution & 8.3 & 2.3 & 2.0 & 22.5 & 13.8 & 38.4 & 0.7 & 0.0 & 1.4 & 0.2 & 7.5 & 0.1 & 0.5 & 0.1 & 2.2 \\
\hline Flaming & 0.9 & 0.4 & 2.0 & 3.8 & 3.2 & 1.6 & 0.1 & 0.0 & 0.3 & 0.1 & 2.6 & 0.0 & 0.0 & 0.0 & 1.1 \\
\hline$\%$ contribution & 5.3 & 2.7 & 12.5 & 23.3 & 20.0 & 9.9 & 0.9 & 0.0 & 1.6 & 0.4 & 16.0 & 0.1 & 0.1 & 0.2 & 7.0 \\
\hline Char burning & 1.3 & 1.0 & 6.3 & 8.1 & 4.8 & 2.3 & 0.4 & 0.0 & 0.2 & 0.2 & 5.7 & 0.0 & 0.0 & 0.1 & 1.7 \\
\hline$\%$ contribution & 4.1 & 3.1 & 19.7 & 25.3 & 14.9 & 7.3 & 1.1 & 0.0 & 0.6 & 0.5 & 17.9 & 0.0 & 0.1 & 0.2 & 5.3 \\
\hline
\end{tabular}

During the ignition phase, both $\mathrm{Si}$ and $\mathrm{K}$ were high because wood was used as kindling to ignite the coal nuggets ( $\mathrm{Xu}$ et al., 2003). In the flaming phase, the percentage contribution of potassium is higher relative to the ignition and char burning phases. The increase of $\mathrm{K}$ during flaming is possibly due to the pyrolysis of the wood kindling. A noticeable decline in potassium percentage contribution can be seen during the char burning phase. For the marker of coal emissions, a relatively steady increase in $\mathrm{Si}$ emission confirms that the particles are from coal combustion. All trace elements emissions except $\mathrm{Ca}$ and $\mathrm{K}$ steadily increased as the combustion progressed. $\mathrm{K}$ and $\mathrm{Ca}$ emissions are thought to be associated with wood kindling, which often burns out in the second half of the flaming stage (Makonese et al., 2014).

In previous studies, the elemental composition from coal-burning boilers/ furnaces was limited to fly ash, with little emphasis on the elemental composition of smoke emissions from various combustion phases (Yi et al., 2008; Vejahati, Xu and Gupta, 2010; Silva et al., 2012). Meij and Winkel (2009) argued that low volatile organic trace elements categorized in class one (i.e. $\mathrm{Al}, \mathrm{Ca}, \mathrm{Ce}, \mathrm{Cs}, \mathrm{Eu}$, $\mathrm{Fe}, \mathrm{Hf}, \mathrm{K}, \mathrm{La}, \mathrm{Mg}, \mathrm{Sc}, \mathrm{Sm}, \mathrm{Si}, \mathrm{Sr}, \mathrm{Th}$ and $\mathrm{Ti}$ ) are comparable in smoke and ash. During coal combustion, the minerals in the coal are deposited as bottom ash, and some are given off as fly ash (Lu et al., 2017). The type of mineral elements released is related to the mineral content of the fuel (Table 2).

Table 2. Comparing percentage contribution elemental species between smoke particles and the fuel.

\begin{tabular}{cccc}
\hline & ICP-MS Results & \multicolumn{2}{c}{ Fuel Analysis Results } \\
\hline Element & \% Contribution & Standard Method & \% Contribution \\
\hline $\mathrm{Si}$ & 23.7 & ASTM D4326 & 58.6 \\
$\mathrm{Al}$ & 11.4 & ASTM D4326 & 27.6 \\
$\mathrm{Fe}$ & 13.8 & ASTM D4326 & 6.6 \\
$\mathrm{Ti}$ & 0.9 & ASTM D4326 & 0.8 \\
$\mathrm{Cr}$ & 1.2 & ASTM D4326 & 0.6 \\
$\mathrm{Ca}$ & 18.5 & ASTM D4326 & 2.3 \\
$\mathrm{Mg}$ & 2.7 & ASTM D4326 & 0.8 \\
$\mathrm{Na}$ & 5.9 & ASTM D4326 & 0.4 \\
$\mathrm{~K}$ & 16.2 & ASTM D4326 & 0.8 \\
$\mathrm{~S}$ & 1.1 & ASTM D4326 & 1.1 \\
$\mathrm{Mn}$ & 0.4 & ASTM D4326 & 0.1 \\
\hline
\end{tabular}


Results in Table 2 provided a comparison on the fuel burned composition and emitted trace elements. The particles emitted contained $\mathrm{K}$; while there was a relative low amount of $\mathrm{K}$ in the coal. This was expected as wood was used as kindling to ignite the coal. These results found traces of elements similar to those described or obtained in the ash by other studies (Meij and te Winkel, 2007; Makonese, 2015; Zhang et al., 2018).

Table 3 shows results of the percentage contributions of trace elements for the three combustion phases. With decreasing volatile matter from the burning fuel, mineral particles dominated the char burning phase. As expected, the bulk of the elements were emitted during the char burning phase relative to the flaming and ignition phases (Zhang et al., 2018). This finding suggests that the majority of particles emitted during the ignition and flaming phases could be dominated by elements and volatile organic compounds (Zhou et al., 2016). During the char burning phase, most non-water soluble trace elements are expected to be released.

Table 3. Percentage contribution of detected elements emitted per combustion phase.

\begin{tabular}{ccc}
\hline Combustion phase & $\begin{array}{c}\text { Total elements } \\
(\boldsymbol{\mu g} / \mathbf{g})\end{array}$ & \multirow{2}{*}{ Contribution } \\
\hline Ignition & 10.1 & 17 \\
Flaming & 16.2 & 28 \\
Char burning & 31.9 & 55 \\
Sum & $\mathbf{5 8 . 2}$ & $\mathbf{1 0 0}$ \\
\hline
\end{tabular}

\section{Conclusion}

This study was conducted to examine the morphology and elemental characteristics of freshly emitted individual particles emitted at three distinct combustion phases in domestic packed-bed domestic coal combustion processes. Three types of particles were classified, viz., spherical organic particles with similar characteristics to tarballs, soot particles, and mineral particles. Spherical organic compounds were predominant in the ignition stage due to smouldering combustion conditions, while soot particles dominated the flaming stage. The identification of spherical organic particles is essential to understand how particles evolve once released into the atmosphere. Mineral particles were predominant in the char burning stage. Elemental composition analysis showed that the particles were rich in $\mathrm{Si}, \mathrm{K}, \mathrm{Al}, \mathrm{Fe}, \mathrm{Ca}, \mathrm{Zn}, \mathrm{Na}, \mathrm{Mg}$, and Ti depending on the combustion phase. The type of mineral elements released was related to the mineral content of the fuel.

This information is essential in updating emission inventory sources, understanding of radiation forcing potential and provide a basis for warming estimation. In addition to the morphology, the information on trace elements can play a role in source identification due to chemical signatures or emission markers. Both $\mathrm{Si}$ and $\mathrm{K}$ were high during the ignition phase indicating simultaneous combustion of wood and coal. In this case, wood was used as kindling. For the marker of coal emissions, a relatively steady increase in Si emission confirmed across the entire combustion cycle indicated the particles were emitted from coal combustion.

\section{Acknowledgement}

This work was done in collaboration with several people or groups. Sincere appreciations to Mr Shalala Mgwambani and Mr Kevin Kasangana for their assistance during laboratory experiments. Mr Siyasanga Mpelane for assisting with TEM analysis. Extended appreciation to Mr Philip Pieterse for assisting with ICP-MS analysis. 


\section{References}

Alexander, D. T. L., Crozier, P. A. and Anderson, J. R. (2008) ‘Brown carbon spheres in East Asian outflow and their optical properties', Science, 321(5890), pp. 833-836. doi: 10.1126/science.1155296.

An, D. et al. (2007) 'Unventilated indoor coal-fired stoves in Guizhou province, China: Reduction of arsenic exposure through behavior changes resulting from mitigation and health education in populations with arsenicosis', Environmental Health Perspectives, 115(4), pp. 659-662. doi: 10.1289/ehp.9273.

Ando, M. et al. (2001) 'Health effects of fluoride pollution caused by coal burning', Science of the Total Environment, 271(1-3), pp. 107-116. doi: 10.1016/S0048-9697(00)00836-6.

Balmer, M. (2007) ‘Household coal use in an urban township in South Africa', Journal Of Energy In Southern Africa, 18(3), pp. 27-32. Available at: http://www.erc.uct.ac.za/jesa/volume18/18-3jesa-balmer2.pdf.

Bond, T. C. et al. (2002) 'Primary particle emissions from residential coal burning: Optical properties and size distributions', Journal of Geophysical Research Atmospheres, 107(21). doi: 10.1029/2001JD000571.

Bond, T. C. et al. (2006) ‘Emission Factors and Real-Time Optical Properties of Particles Emitted from Traditional Wood Burning Cookstoves', 40(21), pp. 6750-6757.

Bonjour, S. et al. (2013) 'Solid fuel use for household cooking: Country and regional estimates for 1980-2010', Environmental Health Perspectives, 121(7), pp. 784-790. doi: 10.1289/ehp.1205987.

Braasch, J. L. G. et al. (2013) 'Please wait ...', Contemporary Educational Psychology, 38, pp. 180-195. doi: 10.1017/CBO9781107415324.004.

Chafe, Z. A. et al. (2015) 'Household cooking with solid fuels contributes to ambient $\mathrm{PM}<\mathrm{inf}>2.5</ \mathrm{inf}>$ air pollution and the burden of disease', Environmental Health Perspectives, 122(12). doi: 10.1289/ehp.1206340.

Chakrabarty, R. K. et al. (2010) 'Brown carbon in tar balls from smoldering biomass combustion', Atmospheric Chemistry and Physics, 10(13), pp. 6363-6370. doi: 10.5194/acp-10-6363-2010.

Chang, M. C. O. et al. (2004) 'Measurement of ultrafine particle size distributions from coal-, oil-, and gas-fired stationary combustion sources', Journal of the Air and Waste Management Association, 54(12), pp. 1494-1505. doi: 10.1080/10473289.2004.10471010.

Chung, C. E., Ramanathan, V. and Decremer, D. (2012) ‘Observationally constrained estimates of carbonaceous aerosol radiative forcing', Proceedings of the National Academy of Sciences, 109(29), pp. 11624-11629. doi: 10.1073/pnas.1203707109.

Cong, Z. et al. (2010) 'Elemental and individual particle analysis of atmospheric aerosols from high Himalayas', Environmental Monitoring and Assessment, 160(1-4), pp. 323-335. doi: 10.1007/s10661-008-0698-3.

Finkelman, R. B. et al. (2002) 'Health impacts of coal and coal use: Possible solutions', International Journal of Coal Geology, 50(1-4), pp. 425-443. doi: 10.1016/S0166-5162(02)00125-8.

Forouzanfar, M. H. et al. (2015) 'Global, regional, and national comparative risk assessment of 79 behavioural, environmental and occupational, and metabolic risks or clusters of risks in 188 countries, 1990-2013: A systematic analysis for the Global Burden of Disease Study 2013', The Lancet, 386(10010), pp. 2287-2323. doi: 10.1016/S0140- 


\section{6(15)00128-2.}

Frey, A. (2014) Finnish Meteorological Institute Contributions Study on Soot and Other Refractory Components From Various Combustion Processes.

Graham, B. et al. (2002) 'Water-soluble organic compounds in biomass burning aerosols over Amazonia 1. Characterization by NMR and GC-MS', Journal of Geophysical Research Atmospheres, 107(20). doi: 10.1029/2001JD000336.

GroundWork (2016) The Destruction of the Highveld: Digging Coal.

Gwaze, P. (2007) 'Physical and Chemical Properties of Aerosol Particles in The Troposphere : An Approach from Microscopy Methods'.

Hand, J. L. et al. (2005) 'Optical, physical, and chemical properties of tar balls observed during the Yosemite Aerosol Characterization Study', Journal of Geophysical Research Atmospheres, 110(21), pp. 1-14. doi: 10.1029/2004JD005728.

He, B., Liang, L. and Jiang, G. (2002) 'Distributions of arsenic and selenium in selected Chinese coal mines', Science of the Total Environment, 296(1-3), pp. 19-26. doi: 10.1016/S0048-9697(01)01136-6.

Huangfu, Y. et al. (2014) 'Effects of moisture content in fuel on thermal performance and emission of biomass semi-gasified cookstove', Energy for Sustainable Development. Elsevier Ltd, 21(1), pp. 60-65. doi: 10.1016/j.esd.2014.05.007.

IARC Working Group on the Evaluation of Carcinogenic Risks to Humans (2010) 'Household Use of Solid Fuels', IARC Monographs on the Evaluation of Carcinogenc Risks to Humans, 95, p. 430. doi: 10.1002/food.19940380335.

Jalava, P. I. et al. (2010) 'Effect of combustion condition on cytotoxic and inflammatory activity of residential wood combustion particles', Atmospheric Environment. Elsevier Ltd, 44(13), pp. 1691-1698. doi: 10.1016/j.atmosenv.2009.12.034.

De Jong, W. H. et al. (2008) 'Particle size-dependent organ distribution of gold nanoparticles after intravenous administration', Biomaterials, 29(12), pp. 1912-1919. doi: 10.1016/j.biomaterials.2007.12.037.

Kimemia, D. and Annegarn, H. (2011) 'An urban biomass energy economy in Johannesburg, South Africa', Energy for Sustainable Development. International Energy Initiative, 15(4), pp. 382-387. doi: 10.1016/j.esd.2011.10.002.

Kocbach, A. et al. (2005) 'Analytical electron microscopy of combustion particles: A comparison of vehicle exhaust and residential wood smoke', Science of the Total Environment, 346(1-3), pp. 231-243. doi: 10.1016/j.scitotenv.2004.10.025.

Köylu, Ü., Xing, Y. and Rosner, D. E. (1995) ‘Fractal Morphology Analysis of Combustion-Generated Aggregates Using Angular Light Scattering and Electron Microscope Images', Langmuir, 11(12), pp. 4848-4854. doi: 10.1021/la00012a043.

Kumar, A. et al. (2014) 'Assessment of indoor air concentrations of VOCs and their associated health risks in the library of Jawaharlal Nehru University, New Delhi', Environmental Science and Pollution Research, 21(3), pp. 22402248. doi: 10.1007/s11356-013-2150-7. 
Kumar, P. et al. (2010) 'A review of the characteristics of nanoparticles in the urban atmosphere and the prospects for developing regulatory controls', Atmospheric Environment. Elsevier Ltd, 44(39), pp. 5035-5052. doi: 10.1016/j.atmosenv.2010.08.016.

Kumarathasan, P. et al. (2018) ‘Cardiovascular and inflammatory mechanisms in healthy humans exposed to air pollution in the vicinity of a steel mill'. Particle and Fibre Toxicology, pp. 1-17. doi: 10.1186/s12989-018-0270-4.

Li, J. et al. (2003) 'Individual aerosol particles from biomass burning in southern Africa: 2, Compositions and aging of inorganic particles', Journal of Geophysical Research: Atmospheres, 108(D13), p. n/a-n/a. doi: 10.1029/2002JD002310.

Lim, S. S. et al. (2012) 'A comparative risk assessment of burden of disease and injury attributable to 67 risk factors and risk factor clusters in 21 regions, 1990-2010: A systematic analysis for the Global Burden of Disease Study 2010', The Lancet, 380(9859), pp. 2224-2260. doi: 10.1016/S0140-6736(12)61766-8.

Liu, J. et al. (2014) 'Brown carbon in the continental troposphere Brown carbon in the continental troposphere Brown carbon in the continental troposphere', Geophys. Res. Lett, 41(10), pp. 2191-2195. doi: 10.1002/2013GL058976.Received.

Liu, Y.et al. (2008) 'Source profiles of volatile organic compounds (VOCs) measured in China: Part I', Atmospheric Environment, 42(25), pp. 6247-6260. doi: 10.1016/j.atmosenv.2008.01.070.

Lu, S. et al. (2017) 'Single particle aerosol mass spectrometry of coal combustion particles associated with high lung cancer rates in Xuanwei and Fuyuan, China', Chemosphere. Elsevier Ltd, 186, pp. 278-286. doi: 10.1016/j.chemosphere.2017.07.161.

Makonese, T. et al. (2014) 'Aerosol particle morphology of residential coal combustion smoke', 24(2), pp. 24-28.

Makonese, T. et al. (2015) 'Influence of fuel-bed temperatures on CO and condensed matter emissions from packed-bed residential coal combustion', Domestic Use of Energy (DUE), 2015 International Conference on the, pp. 63-69. doi: 10.1109/DUE.2015.7102964.

Makonese, T. (2015) 'Systematic investigation of smoke emissions from packed-bed residential coal combustion devices', (April).

Makonese, T. et al. (2017a) 'Emission factors of domestic coal-burning braziers', South African Journal of Science, 113(3-4), pp. 1-11. doi: 10.17159/sajs.2017/20160187.

Makonese, T. et al. (2017b) 'Influence of fire-ignition methods and stove ventilation rates on gaseous and particle emissions from residential coal braziers', Journal of Energy in Southern Africa, 26(4), p. 16. doi: 10.17159/24133051/2016/v26i4a2089.

Makonese, T., Masekameni, D. M. and Annegarn, H. J. (2017) 'Influence of coal properties on the performance of fixedbed coal-burning braziers', Journal of Energy in Southern Africa, 28(2), pp. 40-51. doi: 10.17159/24133051/2017/v28i2a1374.

Masekameni, D. M. et al. (2018) 'Size Distribution of Ultrafine Particles Generated from Residential Fixed-bed Coal Combustion in a Typical Brazier', Aerosol and Air Quality Research, 18(10), pp. 2618-2632. doi: 10.4209/aaqr.2018.03.0105.

Masekameni, D., Makonese, T. and Annegarn, H. J. (2014) 'Optimisation of ventilation and ignition method for 
reducing emissions from coal-burning imbaulas', Proceedings of the 22nd Conference on the Domestic Use of Energy, DUE 2014. doi: 10.1109/DUE.2014.6827755.

Masondo, L. et al. (2016) 'Influence of coal-particle size on emissions using the top-lit updraft ignition method', 26(1), pp. 15-20.

Mathis, U. et al. (2005) 'Influence of diesel engine combustion parameters on primary soot particle diameter', Environmental Science and Technology, 39(6), pp. 1887-1892. doi: 10.1021/es049578p.

Mc Donald, R. and Biswas, P. (2004) 'A methodology to establish the morphology of ambient aerosols', Journal of the Air and Waste Management Association, 54(9), pp. 1069-1078. doi: 10.1080/10473289.2004.10470986.

Meij, R. and te Winkel, H. (2007) 'The emissions of heavy metals and persistent organic pollutants from modern coal-fired power stations', Atmospheric Environment, 41(40), pp. 9262-9272. doi: 10.1016/j.atmosenv.2007.04.042.

Moolla, R., Curtis, C. J. and Knight, J. (2015) 'Assessment of occupational exposure to BTEX compounds at a bus diesel-refueling bay: A case study in Johannesburg, South Africa', Science of the Total Environment. Elsevier B.V., 537, pp. 51-57. doi: 10.1016/j.scitotenv.2015.07.122.

Moreira Dos Santos, C. Y., De Almeida Azevedo, D. and De Aquino Neto, F. R. (2004) 'Atmospheric distribution of organic compounds from urban areas near a coal-fired power station', Atmospheric Environment, 38(9), pp. 1247-1257. doi: 10.1016/j.atmosenv.2003.11.026.

Niemi, J. V. et al. (2006) 'Changes in background aerosol composition in Finland during polluted and clean periods studied by TEM/EDX individual particle analysis', Atmospheric Chemistry and Physics, 6(12), pp. 50495066. doi: 10.5194/acp-6-5049-2006.

Nussbaumer, T. et al. (2001) Aerosols from biomass combustion, International Seminar by IEA Bioenergy Task.

Oberdörster, G. (2001) 'Pulmonary effects of inhaled ultrafine particles', International Archives of Occupational and Environmental Health, 74(1), pp. 1-8. doi: 10.1007/s004200000185.

Petaloti, C. et al. (2006) 'Trace elements in atmospheric particulate matter over a coal burning power production area of western Macedonia, Greece', Chemosphere, 65(11), pp. 2233-2243. doi: 10.1016/j.chemosphere.2006.05.053.

Pósfai, M. et al. (2004) 'Atmospheric tar balls: Particles from biomass and biofuel burning', Journal of Geophysical Research: Atmospheres, 109(D6), p. n/a-n/a. doi: 10.1029/2003JD004169.

Rainey, K. L., Vaganay, M. and MacIntyre, S. (2016) 'A Review of Literature on Residential Solid Fuel Burning, and Consequently the Implications of Meeting the European 2050 Low-Carbon Targets', Journal of Geoscience and Environment Protection, 04(04), pp. 7-13. doi: 10.4236/gep.2016.44002.

Le Roux, L. J., Zunckel, M. and Mccormick, S. (2009) 'Reduction in air pollution using the “ basa njengo magogo " method and the applicability to low-smoke fuels', Journal of Energy in Southern Africa, 20(3), pp. 3-10.

SANS (2005) 'SANS 1929 : 2005 SOUTH AFRICAN NATIONAL STANDARD Ambient air quality - Limits for common pollutants'.

Schneider, J. et al. (2006) 'Mass spectrometric analysis and aerodynamic properties of various types of combustion-related aerosol particles', International Journal of Mass Spectrometry, 258(1-3), pp. 37-49. doi: 10.1016/j.ijms.2006.07.008. 
Silva, L. F. O. et al. (2012) 'Applied investigation on the interaction of hazardous elements binding on ultrafine and nanoparticles in Chinese anthracite-derived fly ash', Science of the Total Environment. Elsevier B.V., 419(July 2007), pp. 250-264. doi: 10.1016/j.scitotenv.2011.12.069.

Sippula, O. (2010) Fine Particle Formation and Emissions in Biomass Combustion. doi: 978-952-5822-15-1.

Smith, K. R. et al. (1994) 'Air pollution and the energy ladder in asian cities', Energy, 19(5), pp. 587-600. doi: 10.1016/0360-5442(94)90054-X.

Smith, K. R. et al. (2007) 'Monitoring and evaluation of improved biomass cookstove programs for indoor air quality and stove performance: conclusions from the Household Energy and Health Project', Energy for Sustainable Development. International Energy Initiative, Inc., 11(2), pp. 5-18. doi: 10.1016/S0973-0826(08)60396-8.

Smith, K. R. et al. (2009) 'Public health benefits of strategies to reduce greenhouse-gas emissions: health implications of short-lived greenhouse pollutants', The Lancet. Elsevier Ltd, 374(9707), pp. 2091-2103. doi: 10.1016/S0140-6736(09)61716-5.

Smith, K. R. and Liu, Y. (1994) 'Indoor Air Pollution in Developing Countries', Epidemiology of Lung Cancer, 74(7), pp. 151-184. doi: 10.1158/1078-0432.CCR-03-0489\n10/13/4314 [pii].

StatsSA (2017) ‘P0302: Mid-year population estimates 2017’, Stats Sa, (July), p. 10. doi: Statistical release P0302.

Streets, D. . and Waldhoff, S. . (2000) 'Present and future emissions of air pollutants in China':, Atmospheric Environment, 34, pp. 363-374. doi: 10.1016/S1352-2310(99)00167-3.

Suzuki, K. (2006) ‘Characterisation of airborne particulates and associated trace metals deposited on tree bark by ICP-OES, ICP-MS, SEM-EDX and laser ablation ICP-MS', Atmospheric Environment, 40(14), pp. 2626-2634. doi: 10.1016/j.atmosenv.2005.12.022.

Thajudeen, T., Jeon, S. and Hogan, C. J. (2015) ‘The mobilities of flame synthesized aggregates/agglomerates in the transition regime', Journal of Aerosol Science. Elsevier, 80, pp. 45-57. doi: 10.1016/j.jaerosci.2014.11.003.

Tissari, J. et al. (2008) 'Fine particle and gaseous emissions from normal and smouldering wood combustion in a conventional masonry heater', Atmospheric Environment, 42(34), pp. 7862-7873. doi: 10.1016/j.atmosenv.2008.07.019.

Tiwari, M. et al. (2014) ‘Particle size distributions of ultrafine combustion aerosols generated from household fuels', Atmospheric Pollution Research. Elsevier, 5(1), pp. 145-150. doi: 10.5094/APR.2014.018.

Torvela, T. et al. (2014) 'Effect of wood combustion conditions on the morphology of freshly emitted fine particles', Atmospheric Environment. Elsevier Ltd, 87, pp. 65-76. doi: 10.1016/j.atmosenv.2014.01.028.

Tóth, A. et al. (2014a) 'Atmospheric tar balls: Aged primary droplets from biomass burning?', Atmospheric Chemistry and Physics, 14(13), pp. 6669-6675. doi: 10.5194/acp-14-6669-2014.

Tóth, A. et al. (2014b) 'Atmospheric tar balls: Aged primary droplets from biomass burning?', Atmospheric Chemistry and Physics, 14(13), pp. 6669-6675. doi: 10.5194/acp-14-6669-2014.

Vejahati, F., Xu, Z. and Gupta, R. (2010) 'Trace elements in coal: Associations with coal and minerals and their behavior during coal utilization - A review', Fuel. Elsevier Ltd, 89(4), pp. 904-911. doi: 10.1016/j.fuel.2009.06.013.

Wang, A. Q. C. and Luo, B. Y. H. (2009) 'Application SEM to analysis formation characteristic of soot aerosol 
emitted from lump-coal combustion in fixed-bed', Asia-Pacific Power and Energy Engineering Conference, APPEEC, pp. 2-5. doi: 10.1109/APPEEC.2009.4918190.

Wang, W. et al. (2018) 'Characteristics of Individual Particles Emitted from an Experimental Burning Chamber with the Coal from Lung Cancer Area of Xuanwei, China', Aerosol and Air Quality Research, pp. 1-9. doi: 10.4209/aaqr.2018.05.0187.

Wei, W. et al. (2012) 'Emissions of carbon monoxide and carbon dioxide from uncompressed and pelletized biomass fuel burning in typical household stoves in China', Atmospheric Environment. Elsevier Ltd, 56, pp. 136142. doi: 10.1016/j.atmosenv.2012.03.060.

Wentzel, M. et al. (1999) 'Giant dendritic carbonaceous particles in Soweto aerosols', South African Journal of Science, 95(3), pp. 141-145.

Wilkinson, P. et al. (2009) 'Public health benefits of strategies to reduce greenhouse-gas emissions: household energy', The Lancet, 374(9705), pp. 1917-1929. doi: 10.1016/S0140-6736(09)61713-X.

Winkler, H. (2005) ‘Renewable energy policy in South Africa: Policy options for renewable electricity', Energy Policy, 33(1), pp. 27-38. doi: 10.1016/S0301-4215(03)00195-2.

Winkler, H. (2007) 'Energy policies for sustainable development in South Africa', Energy for Sustainable Development. International Energy Initiative, Inc., 11(1), pp. 26-34. doi: 10.1016/S0973-0826(08)60561-X.

Xu, M. et al. (2011) 'Coal combustion-generated aerosols: Formation and properties', Proceedings of the Combustion Institute. Elsevier Inc., 33(1), pp. 1681-1697. doi: 10.1016/j.proci.2010.09.014.

Yi, H. et al. (2008) ‘Fine particle and trace element emissions from an anthracite coal-fired power plant equipped with a bag-house in China', Fuel, 87(10-11), pp. 2050-2057. doi: 10.1016/j.fuel.2007.10.009.

Zhang, H. et al. (2012) 'Chemical and size characterization of particles emitted from the burning of coal and wood in rural households in Guizhou, China', Atmospheric Environment. Elsevier Ltd, 51, pp. 94-99. doi: 10.1016/j.atmosenv.2012.01.042.

Zhang, J. et al. (2000) 'Greenhouse gases and other airborne pollutants from household stoves in China: A database for emission factors', Atmospheric Environment, 34(26), pp. 4537-4549. doi: 10.1016/S1352-2310(99)004501.

Zhang, J. and Smith, K. R. (2007) 'Household air pollution from coal and biomass fuels in China: Measurements, health impacts, and interventions', Environmental Health Perspectives, 115(6), pp. 848-855. doi: 10.1289/ehp.9479.

Zhang, R. et al. (2008) 'Variability in morphology, hygroscopicity, and optical properties of soot aerosols during atmospheric processing', Proceedings of the National Academy of Sciences, 105(30), pp. 10291-10296. doi: 10.1073/pnas.0804860105.

Zhang, R. et al. (2018) 'Morphology and property investigation of primary particulate matter particles from different sources', Nano Research, 11(6), pp. 3182-3192. doi: 10.1007/s12274-017-1724-y.

Zhou, M. et al. (2015) 'Smog episodes, fine particulate pollution and mortality in China', Environmental Research. Elsevier, 136, pp. 396-404. doi: 10.1016/j.envres.2014.09.038.

Zhou, W. et al. (2016) 'Evolution of submicrometer organic aerosols during a complete residential coal 
combustion process', Environmental Science and Technology, 50(14), pp. 7861-7869. doi: 10.1021/acs.est.6b00075. 